\title{
Clinical Challenges in Working with Asian Immigrant Women and Their Families
}

\author{
Muriel $\mathrm{Yu}^{1} \&$ Tuyen D. Nguyen ${ }^{2}$ \\ ${ }^{1}$ University of Texas at Arlington, USA \\ ${ }^{2}$ California State University, USA \\ Correspondence: Tuyen D. Nguyen, PhD, California State University, USA. E-mail: \\ trentspringfield@yahoo.com
}

Received: December 9, 2011

Accepted: February 14, 2012 Published: June 1, 2012

doi:10.5539/ass.v8n7p11

URL: http://dx.doi.org/10.5539/ass.v8n7p11

\begin{abstract}
This counseling-practice oriented paper examines clinical challenges that therapists face in working with Asian immigrant women and their families. Salient Asian cultural factors are discussed to help non-Asian therapists gain a better understanding of their Asian clients in a therapeutic relationship. A clinical case vignette is incorporated in the paper to illustrate how cultural factors influence Asian immigrant women and their families in therapy. A case-study method was employed in this present study as a method of data collection. The results reflect that cultural competence is greatly needed when working with Asian immigrant women and their families, taking into consideration the systemic nature of this population's ways handling both individual and familial struggles with mental health issues. Lastly, the paper offers therapists/clinicians culturally sensitive therapeutic assessment and intervention strategies that are deemed effective in working with Asian immigrant women and their families struggling with mental health issues.
\end{abstract}

Keywords: Asian population, therapy \& Asian immigrant women, mental health \& Asian families

\section{Introduction}

Asian immigrant women encounter multiple hardships and tasks that are not only demanding but also life challenging after their resettlement in the United States. They present different challenges to mental health therapists due to gender and cultural conditioning. Women immigrants and refugees have long been declared the most vulnerable and at risk population (Martin, 2004). While many western countries receive immigrants and refugees, the United States leads the world in number of immigrants and refugees, with a net migration of 960,000 between 1996-2001, and accounts for $27 \%$ of the world's total international immigrants (Doyle, 2002). According to Office of Immigration Statistics (2004), total migration to U. S. in 2003 was 833,593 with a large percentage of this population being women and children.

Asian immigrant women as with other immigrant women suffer from many health and mental health disorders due to stressors related to their pre-migration, in transit experiences and post migration adjustments. Their cultural background and rigid gender prescribed role functions add complexity when therapists are engaged to render clinical services to this population. Their lack of English language skills further compounds clinician-client relationship and intervention effectiveness. When faced with severe mental illness Asians immigrant women and their families often experience hardship in accessing services that are available and culturally competent in meeting their needs. Conversely, Asian Americans also have a strong sense of familial piety and they bring a value of communal relationships which extends to their interactions with professional helpers. Their strong sense of responsibility toward each other in the family and respect of people in authority may motivate them to move in the directions of positive behavior changes when entering into a therapeutic relationship (Lee, 1997; Kim \& Keefe, 2009). Therefore, therapists who possess sound judgment and culture-specific knowledge and tools can be effective in connecting with these women and their families by offering timely and cultural competent services in the community.

In general, the system framework bears significant advantages in making effective clinical interventions because of its emphasis on the interconnectedness of all important components of clients' life experiences and the broader social and cultural environment. Given that broad perspective, therapists can mentally place clients in a 
multi-dimensional space which in turn provide a systemic way of looking at the client's environmental factors including sources of distress as well as resources available to the client. Once these overall determinants are made one can focus on specific approaches and particular techniques appropriate for an individual client and her family.

A culturally competent intervention approach requires a therapist's ability to establish a trusting relationship and provide appropriate timely intervention while honoring client's cultural beliefs and traditions (Schultz, 2004). Additionally, a culturally competent therapist must select modalities/ approaches proven to yield positive outcome. Increasingly, the term Evidence-Based Practice has been discussed in the literature and practice settings. The Institute of Medicine defines Evidence-Based Practice as "the integration of best research with clinical expertise and patient values" (Sackett, Straus, Richardson, Rosenberg, \& Havnes, 2000, p.138). It is gaining more attention and currently considered a hallmark of excellence in clinical practice in the field of mental health (McNeill, 2006). EBP requires a foundation of clinical skills and relevant knowledge about the particular population served including values about the nature of the external world and the implications for the experiences of those who live in it (McNeill, 2006). For culturally competent therapists working with seriously mental ill Asian immigrant women and their families, it is essential that sound therapeutic interventions should include relevant clinical knowledge and skills while respecting their cultural values and traditions to insure professional and ethical integrity.

This article will discuss traditional Asian cultural impact on Asian Americans' belief systems, coping behaviors, family dynamics and clinical challenges a therapist may encounter in a therapeutic relationship. Special considerations in making assessment and selecting therapeutic approaches and relevant intervention techniques are presented. Using a case example in working with a Chinese American immigrant woman and her family, the authors will discuss gender and cultural influences on Asian American women; theories of acculturation and its implications for clinical practice; useful assessment tools and measurements; and effective intervention approaches. It is hoped that the wider applicability and usefulness of the discussion will benefit other clinicians who work with a similar population.

\subsection{Asian Immigrants}

Asian immigrants have been coming to the United States at many different times throughout history to the present. They have been considered the "model" minority. This success stereotype, however, draws attention away from the pressures that Asian immigrants have continued to face in their new environment (Chung, 2001). Even though Asian immigrants have come to the United States from many different areas throughout Asia, they have all faced similar pre-migration experiences of leaving behind their family members and friends in their homelands. Some of them also had pre-migration experiences of rape, loss of family members, and living under the constant threat of torture or death, making them further at risk for developing serious psychological disorders (Mollica, Wyshak, \& Lavell, 1987; Lee, Joun, Martinez, Hsu, Robinson, Bawa, \& Ma, 2009). Through this loss of significant others in their lives, they would have emotionally painful, lonely, and isolating experiences, thus making them more vulnerable to mental health issues (Akhtar \& Choi, 2004).

The first generations of Chinese and Japanese immigrants began coming to the United States to work in mining, farming and railroad as early as the 19th century (Hirayama, 1990; Lin, 2003). They were followed by Korean and Filipino immigrants who came to work in the sugar cane plantations in Hawaii (Min, 1995). The number of Asian immigrants continues to grow due to the economic issues and political conflicts in their homelands. At the end of the Vietnam War, in 1975, many people from Vietnam, Cambodia, and Laos escaped the countries to come to the United States for political, social, and economic opportunities. The majority of them escaped in homemade, poorly constructed boats and wooden vessels. Due to the numerous attacks by Thai pirates, the death rate of those refugees was very high and because of their numerous traumatic experiences, many Asian immigrants have since experienced depression, anxiety, alienation, a sense of helplessness, and post traumatic stress disorder (Mollica, et al. 1987; Nagai, 2008).

While Asian immigrants have come from varied cultural backgrounds with different values, customs, beliefs, social practices and religions, they face similar psychosocial adjustments. Learning a new language is a major aspect of Asian assimilation in terms of finding a job, acquiring new skills and attaining a career relative to their status, experience and expectation (Hinton,Tiet, Tran, \& Chesney, 1997). Beyond adjusting to the United States economically as quickly as possible in order to support the needs of their families, comes the realization that for many Asian immigrants who do speak English fluently and already have college degrees of being forced to accept employment for which they are over-qualified (Lin, Inui, Kleinman, \& Womack, 1982) 
Akhtar and Choi (2004) revealed that Asian immigrants living separated from their homeland face specific challenges in the dominant society of the United States. These include those of the empty nest, the lack of respect from their children, and the loneliness associated with retirement that has them approaching the issues of death with far greater isolation and despair. Research has shown that Asian immigrants who successfully have come to the United States but who had left family members and friends behind in their homelands or who had witnessed torture or killings while escaping their countries have continued to be haunted by feelings of intense anxiety and guilt (Lin et al., 1982; Svensson, Nygard, Sorensen, and Sandanger, 2009).

\section{Culture, Acculturation and Gender Considerations}

Culture is a powerful influence on one's total being - behaviors, thinking, feelings, attitudes, values, and beliefs (Phan, Rivera \& Roberts-Wilbur, 2005). An individual's cultural identification is a complex process that can be conscious or unconscious depending on an individual's level of awareness (Hong \& Ham, 2001). Acculturation, on the other hand, is a process whereby one gradually takes on host country's cultural values and beliefs while maintaining one's cultural values from country of origin (Diller, 2002). It is multi-dimensional and as a psychological phenomenon it can impact an individual's identity formation. Conversely, one's stand on the acculturation continuum also influences the individual's cultural identity, beliefs, values, and behaviors (Yeh \& Hwang, 1996). Culturally competent therapists need to assess the extent of an Asian immigrant woman and her family's traditional cultural influences, their cultural identity, and their stands on various dimensions of acculturation to form accurate evaluations of presenting concerns, expressed emotions and behaviors (Diller, 2002).

In evaluating family and individual members' standing on various acculturation dimensions, therapists need to be aware that researchers have not been consistent in its definitions or important dimensions to include in its measurement (Anderson, Moeschberger, Chen, Junn, Weavers \& Guthrie, 1993). However, most agreed that acculturation process include changes in behavior and values or movements from the values and social behaviors of one culture to another. Most acculturation scales measure one's language usage and proficiency, preferred life style in clothing and food, rituals and holiday celebration, membership in social and religious institutions and value and attitude orientation (Anderson et al., 1993; Nagai, 2008). Several acculturation scales for Asian Americans exist. A most commonly used assessment tool of acculturation for Asian Americans is the Suinn-Lew Asian Self-Identity Acculturation Scale (Lee \& Liu-Tom, 2006). Others include the Asian American Multidimensional Acculturation Scale (Chung, Kim \& Abreu, 2004) and Acculturation Scale for Southeast Asians by Anderson, Moeschberger, Chen, Kunn, Wewers \& Guthrie (1993).

Gender is another important variable that impacts therapeutic considerations as psychosocial development and life experiences between male and female are different in all societies and the differences are more prominent in Asian societies. In all cultures women need to enlarge their views of themselves because of societies' differential treatment between male and female. However, Asian culture imposes more rigid gender role assignments and performances for women so power and status differentiation in society between men and women are more extreme. As a result, many Asian American women clients may suffer from internalized low self-esteem and self-blame when experiencing interpersonal relationship conflicts or other psychological difficulties (Lee, 1996; Tewary, 2005). These factors combined with traditional Asian cultural values of family loyalty, honor, harmony, and collective well being (versus individualism) often add complexity in making accurate assessment and clinical judgment.

\section{Assessment, Therapeutic Approaches and Challenges}

\subsection{Assessment}

A comprehensive assessment is one of the key elements in competent clinical practice. A multi-dimensional assessment framework is particularly useful in working with Asian immigrant women and their families. Areas of evaluation may include social class, migratory history, English language use and proficiency, contact with cultural institutions - ethnic churches, schools and social club; holidays and special events; life-cycle transitional events such as birth, marriage and death; and past and current crises and stressors (Yu, 1999). A more general tool to assess Asian Americans' cultural background is the Culturagram by Congress (1994). Other scales discussed earlier render additional useful information on individual family members' cultural identity and their stands on various acculturation dimensions. This and other tools and measurements are to be augmented by therapists' own observations and evaluation since clients' culture-specific indicators need to include demonstrated behaviors, expression of feelings, and thinking (Ward, 1996; Trevedi, Mishra, Kendurkar, 2007). 


\subsection{Therapeutic Approaches and Challenges}

Writings on effective therapeutic intervention approaches for Asian Americans often discuss the merits of direct, solution focused and problem-solving approaches as treatment of choice (Berg, 1992; Chien \& Benerjee, 2002; Dana, 1998; Ng, 2003; Wasan, Neufeld, \& Jayaram, 2009). Being Asian American therapists and educators and having worked with this population, the authors find the effectiveness of these approaches can be increased when combined with other approaches in working with Asian American women and their families. In particular, the concept of assimilative integration therapeutic approach by Messer (2001) seems to be of particular value in working with Asian Americans because of its inclusiveness and flexibility.

\subsection{Assimilative Integration Is a New Type of Psychotherapy Integration}

After a review of existing literature of psychotherapy integration and its practices, Lampropoulos (2001) concludes that assimilative integration can be the best theoretically and empirically based integrative approach available at this time because it serves as a bridge between theoretical integration and theoretical eclecticism. Others suggest that assimilative integration is especially practicable for psychotherapists who have been trained in a single mode of therapy before becoming integrationists (Frank, 2001). For example, Watchel (2001) writes of his methods of seamlessly assimilating techniques from a behavioral approach into a psychodynamic therapy by providing his own case examples. Others also wrote of the value of integrating approaches and techniques in an assimilative model such as psychodynamic attitudes within a cognitive-behavioral therapy, active interventions within a psychodynamic treatment and Western and Eastern approaches (Messer, 2001; Wong, Chan, \& Leung, 2006). The pluralistic tradition holds that one theory or model can never preempt or preclude an alternative organization of the evidence in psychotherapy. Safran \& Messer (1997) state: "we need several theories at any one time because the best way of approaching the truth is through the ongoing confrontation of multiple, competing theories with each other and with the evidence" (p. 187).

The authors recognize the reality of therapists' theoretical persuasion and the merits of using a single therapeutic model in working with their clients. As more knowledge is gained by working with culturally diverse populations, it is possible that therapists will become more open to a broader pluralistic perspective in order to accommodate culturally dissimilar clients' specific psychosocial needs. The following case example demonstrates the concept and process of applying an assimilative integration approach in working with a seriously mentally ill Chinese immigrant woman and her family. Clinical challenges and cultural competent intervention strategies are discussed

\section{The Case of Mrs. Chan and Her Family}

A young 19 year old Chinese American woman requests the service of a mental health therapist in a large southwest metropolitan community on $10 / 1 / 2008$. She identifies herself as the daughter whose mother age 42 , is emotionally ill and needing intervention. She speaks fluent English but her mother, Mrs. Chan, needs a mental health professional who can speak Cantonese (one of the main Chinese dialects). She is much relieved to locate a therapist who can speak this dialect because the family has frantically been searching for one to two weeks without success.

Due to her youth and her Asian heritage, the therapist asks to speak to her parents to continue the conversation. She agrees to have them call back after their return from their visit to an acupuncturist.

\subsection{Family Background}

The family came to United States from China about ten years ago. The father works as a mechanic in a large industry and the mother sews as a contract garment laborer. There are two children, the young woman who makes the telephone call is a college freshman on summer vacation and her older brother, a college junior also at home on summer vacation.

According to the young woman, the mother had a similar "nervous breakdown" 10 years ago shortly after their arrival in this country. The daughter was very young at the time but remembers her mother going back to China to attend the maternal grandmother's funeral and stayed there for six months. While in China, Mrs. Chan was treated by her physician brother with medication and she came back to this country well.

For the first five years after their immigration to the U. S. Mr. Chan, along with his wife did contract garment work during the day and went to vocational school at night. After completing his training Mr. Chan finds a stable job in a large industry as a mechanic. He works hard and is rewarded with rapid career advancement. Mrs. Chan, on the other hand, having no marketable and language skills, continues with her long hours of sewing at home alone. The whole family, including the children, used to help with the sewing after work or school to earn extra 
income. The family's hard work seems to have paid off because their financial situation improved. Currently, they live in a nice home in the suburb and both children are enrolled in private out of state universities.

While the rest of the family seemed to be doing well, Mrs. Chan becomes more withdrawn and isolated. She developed serious sleep and eating disorders for several months and her symptoms gradually became more severe that she stayed up all night, is totally un-responsive to her environment during waking hours--staring into space for long period of time and refused to eat when urged by her family.

\subsection{Assessment}

On the surface this family mirrors many other immigrant families: Struggling with survival issues financially due to parents' lower educational status, limited marketable skills, lack of English language skills, and social isolation among others. As with many other immigrants, the family also shows remarkable strength in quickly developing necessary adaptation skills to their new environment and adjusting to changes without previous supportive systems. However, there are differences between Mrs. Chan and the rest of the family in their coping ability and resiliency to stress.

As a family, the Chans appear to be more traditional in their Asian cultural beliefs and practices when evaluated by using Congress' Culturalgram (1994) and Asian American Multi-dimensional Acculturation Scale by Chung and his colleagues (2004). Indicators include the language used at home--Chinese only, their celebrations of holidays and events--Chinese New Years, August Moon Festivals among others, and their health belief system--their visits to traditional healing modalities such as acupuncture. When looking at individual member' acculturation stand on various dimensions, there is a distinct difference between Mrs. Chan and the rest of the family. These dimensions include language used/preferred, outside contacts with mainstream individuals and social institutions and values and beliefs. These differences can be attributed to their age when arriving in the United States and many biological and psychosocial variable - physical constitution, personality hardiness, childhood experiences among others.

For the Chan family, another variable, Asian cultural influences and gender inequality, also contribute to the differences among family members' adjustment and acculturation process. Because during the individual therapy sessions Mrs. Chan revealed that another family member, the senior Mrs. Chan lived in the home when the family first immigrated to U.S. Mr. Chan had limited contact with his mother as his parents are divorced and he lived with his father. His mother contacted him and asked to live with them in their newly adopted country when she learned of their migration plan. Because the senior Mrs. Chan was abused by her own mother-in-law while in China, she was emotionally abusive toward Mrs. Chan. In the old Chinese tradition, it is customary that this kind of ill treatment (both emotional and physical) was passed on from one generation to another. Most Asian women are forced to endure the abuse due to the low status of women in society and at home as discussed earlier. In addition, in order to preserve family harmony and insure well-being of the family unit as dictated by Asian cultural values, Mrs. Chan suffered the pain in silence.

An additional stressor occurred when her mother died soon after arriving in the United States. The sudden and unexpected death may have exhausted all her previous coping energy and caused her the previous "emotional break-down" ten years ago. It was fortunate that she responded well to medication which enabled her to function well until recently.

For the next few years the family becomes more settled in their new environment and way of life. As the family becomes more stabilized its structure and dynamics changed again when her children entered college and moved away first her son and then her daughter. The children are doing well academically and socially in school and Mr. Chan continues to enjoy his career success and socializing with co-workers. Once more, Mrs. Chan seems to become more isolated. Her children have left the nest, husband busy at work, leaving her home sewing all day long without much meaningful outside contact. Realistically, in her mind, her lack of English language skill and cultural influences of parental obligation to support her family including paying her children's expensive out of state private college tuitions, deprive her of other viable options. In the meantime, her husband and children due to their English skills and socialization opportunities are more integrated in the mainstream society-work and school-related activities; community involvement including Boys/Girls Scouts and church activities; among others.

\subsection{Intervention}

The assimilative integration model by incorporating theoretical conceptualizations and techniques from several intervention approaches was utilized in the intervention process. Specifically, Psychodynamic, Integrative problem-centered therapy and Solution-focused therapy were integrated into working with Mrs. Chan and her 
family to optimize on each approach's relevancy and effectiveness. This model was effective in addressing Mrs. Chan's serious mental illness while re-structure the family system concurrently to make lasting positive changes.

Traditional psychodynamic approach is not a treatment of choice for Asians Americans because they often expect clinicians to take an active, directive, and instructional role in the helping process (Tseng, 2004). Psychodynamic models are complex to evaluate as they are concerned with meaning as well as behavior and it is under-represented in the empirical literature. On the other hand, one of their strengths is the conceptualization aspects of the treatment relationship (Brandell, 2004). Since Asian Americans and Asian American women in particular value personal relationship some Psychodynamic therapy knowledge and techniques are suitable for intervention with Asian American women. For example, the hierarchical transference phenomenon can be a useful concept and tool for effective therapeutic intervention with this population.

Developed by William Pinsof and his colleagues, Integrative problem-centered therapy provides a multilevel model for understanding how family problems are maintained and it emphasizes some important domains including the biological factors and the self system (Nichols \& Schwartz, 1998). The other approach, Solutionfocused brief family therapy is based on the premise of the solution-focused theory that clients tend to already have solution within themselves. Empirically- based research studies conducted at the Family Therapy Center and elsewhere have shown its effectiveness (deShazer, 1991; Lee, 1997). Song (1997) discusses many particular advantages of solution-focused therapy in working with some Asian families.

\subsection{Therapeutic Process and Clinical Challenges}

First contact with Mrs. Chan takes place in her home as she refuses to go to the clinic for an interview. She is home alone by request during the home visit. Judging by her appearance, verbal description of her symptoms and constant movements and pacing throughout her house during the interview, it is evident that she is having a major depressive episode. An urgent clinical judgment is required as to whether to have her hospitalized immediately or refer her for medication consultation while providing intensive therapy on an outpatient basis. This presents a serious clinical challenge and an ethnical dilemma: weighting the client's safety concerns against the risk of her potentially developing a psychotic episode while in the hospital. For it is reasonable to anticipate that Mrs. Chan who refuses to go to an outpatient clinic would most likely decompensate rapidly if forced to enter a much more restricted environment of a hospital. Her inability to communicate with hospital staff who are most likely to be English speaking only would have further traumatized her. In the end, the decision to maintain her at home with medication and therapeutic support proves to be a correct choice with positive outcome. For she responded well to medications prescribed by her physician and the intense outpatient psychotherapy provided by this therapist.

Using the psychodynamic approach, strong and consistent support to Mrs. Chan in individual sessions at the beginning the therapist establishes a trusting relationship with her quickly. Being of the same gender and nationality and speaking the same language while demonstrating knowledge and expertise in providing necessary care the therapist enhances the hierarchical transference between her and Mrs. Chan. This results in the client's willingness to reveal past victimization by her mother-in-law and a growing sense of disconnect with her immediate family members - her husband and children.

Given the proven effectiveness of multi-system's approach in insuring positive long term changes for the identified patient and her environment family therapy is instituted next. Conducting family therapy while one member is in the midst of a major depressive episode presents another serious clinical challenge. In conducting family sessions this therapist has to be cognizant of Asian cultural dictate of strict hierarchal relationships and boundaries between generations as well as Mrs. Chan's fragile emotional state of being. For instance, exposing information shared with the therapist in individual sessions to other family members has to be done with caution to protect individual members' sense of loyalty to one another and without violating generational boundary issues. With the aforementioned in mind, during family sessions, the biological aspects of Mrs. Chan's illness is discussed first. Knowledge of biological causes of mental illness provides a sense of relief for the husband and children as it frees them from a sense of guilt and neglect. The educational process allows the therapist a bridge upon which to build rapport and forming an alliance with each member of the family. For the first time, Mrs. Chan also realizes how her behavior, while not entirely voluntary due to her biological make-up, had caused her family a great deal of pain as well.

To further assist the family members in understanding how family problems are maintained the psychosocial aspects contributing to Mrs. Chan's illness is discussed. Family members for the first time realize the impact of the senior Mrs. Chan's abusive behavior and her own mother's sudden death in the past may have contributed to Mrs. Chan's previous poor mental health and her previous episode of emotional illness. Mr. Chan becomes 
defensive. He denies any knowledge of the extent of the abuse and vows not to allow his mother to come back to their home if she should request it in the future. Mrs. Chan and the children keep silent in deference of their respect of Mr. Chan, a male and head of household as required by Asian tradition and customs. The therapist renders support to Mr. Chan by acknowledging his devotion to his wife and children and his willingness to protect his wife from his mother in the future. Using the strength perspective the whole family is commended for their individual strengths and resiliency evidenced by their achievements in their newly adopted country. This process enabled a new sense of family cohesiveness to develop which aids in Mrs. Chan's recovery from her illness and re-establishing family unity.

To further increase family members in understanding the differences of adjusting and adapting to a new culture and environment between them and Mrs. Chan, the impact of age, gender and socialization opportunities is discussed. Specifically, the impact of Mrs. Chan's traditional role as a caring responsive mother and wife, her lack of English language ability and long hours of working alone at home causing her to feel extremely isolated and lonely is discussed. The family members are asked to suggest things they can do to help their ill wife/mother. Due to Asian family hierarchical structure, the children hesitate to engage in the process at first. Mr. Chan expresses his frustrations over their failed attempts in engaging Mrs. Chan in social activities with family and friends in the past. The children begin to name past school and community events which they wish their mother would have participated. Their sentiments are acknowledged readily by the therapist and they are praised for their love and caring for their wife/mother. Re-directing the focus to the present, the father and children are asked again what are the things they can do now to assist Mrs. Chan in reducing her sense of isolation. A breakthrough comes when the daughter suggests they can have regular family eat-out nights since they all enjoy good Chinese food. To instill a sense of self-responsibility and control in Mrs. Chan she is encouraged to speak out as to what other activities she would enjoy doing to help improve her symptoms - eating, sleeping, and fatigue. After some prodding from everyone she finally says she enjoys just walking around the neighborhood with one of her family members in the evenings after supper. These examples cited above render support to Solution-focused theory of individual and family possess innate ability to find answers to solve their own problems.

\subsection{Outcome and Reflection}

Results and accountability are essential in all clinical settings with any intervention approaches (Walsh, 2003). Relevant questions for both clients and clinicians should include the followings at a minimum:

1). Does the client demonstrate positive changes in emotion and behavior?

2). Is the client able to maintain gains and set new directions and goals after intervention has ended?

3). Evidence of both client and clinician's sense of pride and satisfaction after the relationship has ended.

Upon re-examining the case dynamics and intervention approaches taken, positive outcomes on the three questions posed by Walsh were achieved. First, Mrs. Chan's affect improved significantly during the therapeutic process. While oblivious to her surroundings and disengaged with her whole family initially, she began to show emotions - tears appeared when her children were talking of their pains in watching her declining physical health and mental health. She also became more expressive in communicating her needs to her family (which is significant considering her Asian cultural conditioning and lack of acculturation to western way of behavior). In subsequent follow-up sessions with Mr. and Mrs. Chan after the children have gone back to school, it was learned that they continue to enjoy many activities as a couple. Mrs. Chan further reported that she had resumed practicing her English with tapes and taking time to watch TV to increase her language skills which she once did when she first arrived but had to give it up because of her work demands. Finally, due to the many unique challenges involved with this case discussed earlier, this therapist gained a sense of satisfaction for having provided an effective culturally competent intervention to an Asian family in a serious crisis state.

\section{Conclusion}

Asian immigrant women and their families present challenges to therapists because of many cultural dissimilarities between Asian culture and mainstream United States culture, lack of language proficiency and environmental constrains such as accessibility to culturally knowledgeable mental health professionals. Asia is diverse with many nationalities and ethnic groupings. While there are similarities among certain Asian ethnic groups, attributes such as language, religious beliefs, and the degree of western influences, to name a few, vary significantly from country to country. Stereotyping any cultural groups indiscriminately without considering individual and situational differences is a serious mistake for therapists and can lead to negative outcome for both clients and therapists. Gender inequality and women's low status in society are more prominent in Asian 
society than the western world. Family loyalty, harmony and responsibilities to children's well-being often cause women to defer their own needs to others in the family. Conversely, Asian cultural influences on family loyalty and responsibility and their respect for authority may be a strength when facing life's setbacks such as having a seriously mentally ill family member; for they may be willing to align with the therapist to change behaviors to help the ill member to recover, thereby strengthen the whole family unit. Individual therapists need to be sensitive and be open to learn from clients of certain important cultural and gender factors to augment clinical skills and judgment. Qualified and competent clinicians will be able to select appropriate therapeutic approaches, skills and techniques by using a broad comprehensive system perspective and be disciplined to practice within a culturally competent and evidence-based framework.

\section{References}

Anderson, J. Moeschberger, M. Chen, M. S. Kunn, P. Wewers, M., \& Guthrie, R. (1993). An acculturation scale for Southeast Asians. Social Psychiatry \& Psychiatric Epidemiology, 28, 134-141. http://dx.doi.org/10.1007/BF00801744

Berg, I. K. (1992). Family based service. Milwaukee, WI: Brief Family Therapy.

Brandell, J. P. (2004). Psychodynamic Social Work. New York: Columbia University Press.

Chien, W. W., \& Banerjee, L. (2002). Caught between cultures: The young Asian American in therapy. In E. Davis-Russell (Ed.), California school of Professional Psychology handbook of multicultural education, research, intervention and training. San Francisco: Jossey-Bass.

Chin, J. L. (1994). Psychodynamic approaches. In L. Comas-Diaz \& B. Greene (Eds.), Women of Color: Integrating ethnic and gender identities in psychotherapy (pp. 194-222). New York: Guildford Press.

Chung, R. Kim, B., \& Abreu, J. (2004). Asian American Multidimensional Acculturation Scale: Development, analysis, reliability, and validity. Cultural Diversity \& Ethnic Minority Psychology, 10(1), 66-80. http://dx.doi.org/10.1037/1099-9809.10.1.66

Congress, E. (1994). The use of culturalgrams to assess and empower cultural diverse families. Family in Family in Society, 75, 531-540.

Dana. R. H. (1998). Asian and Asian Americans. In R. H. Dana (Ed.), Understanding cultural identity in intervention and assessment. Thousand Oaks, CA: Sage.

deShazer, S. (1991). Putting difference to work. NY: Norton.

Diller, J. V. (2002). Cultural diversity ( $2^{\text {nd }}$ ed.). Belmont, CA: Brooks/Cole.

Frank, K. A. (2001). Further thoughts about assimilative integration. J. of Psychotherapy Integration, 11(1), 133-154. http://dx.doi.org/10.1023/A:1026689310753

Hong, G. K., \& Ham, M. (2001). Psychotherapy and counseling with Asian American Clients. Thousand Oaks, CA: Sage.

Kim, W., \& R.H. Keefe. (2009). Examining health-related factors among an ethnically diverse group of Asian-American mental health clients. Journal of Evidence-based Social Work, 6(1), 17-28. http://dx.doi.org/10.1080/15433710802633288

Lampropoulos, G. K. (2001). Bridging technical eclecticism and theoretical integration: Assimilative integration. Journal of Psychotherapy Integration, 11(1), 5-19. http://dx.doi.org/10.1023/A:1026672807119

Lee, E. (1996). Asian American families: An overview. In M. McGoldrick \& Giodano, J. (Eds.), Ethnicity and family therapy ( $2^{\text {nd }}$ ed.). NY: Guildford Press.

Lee, E. (Ed.). (1997). Working with Asian Americans: A guide for clinicians. New York: Guilford Press.

Lee, R. M., Yoon, E., \& Liu-Tom, H. (2006). Structure and measurement of acculturation/enculturation for Asian Americans using the ARMA-II. Measurement and Evaluation in Counseling and Development, 39, 42-55.

Lee, S., H. Juon, G. Martinez, C.E. Hsu, E.S. Robinson, J. Bawa, \& G.X. Ma. (2009). Model minority at risk: Expressed needs of mental health by Asian American young adults. Journal of Community Health, 34(2), 144-52. http://dx.doi.org/10.1007/s10900-008-9137-1

McNeill, T. (2006). Evidence-based practice in an age of Relativism: Toward a model for practice. Social Work, 51(2), 147-156. http://dx.doi.org/10.1093/sw/51.2.147

Messer, S. B. (2001). Introduction to the special issue on assimilative integration. J. of Psychotherapy 
Integration, 11(1), 1-4. http://dx.doi.org/10.1023/A:1026619423048

Nagai, C. (2008). Clinicians' self-assessment of cultural and spiritual competency: Working with Asians and Asian Americans. Community Mental Health Journal, 44(4), 303-9. http://dx.doi.org/10.1007/s10597-008-9131-1

Ng, K. S. (1999). The practice of Family Therapy with Asian families. In K. S. Ng (Ed.), Counseling Asian families in Systems perspective. Alexandra, VA: American Counseling Association.

Phan, L. T., Rivera, E. T., \& Roberts-Wilbur, J. (2005). Understanding Vietnamese refugee women's identity development from a sociopolitical and historical perspective. J. of Counseling \& Development, 83, 305-312. http://dx.doi.org/10.1002/j.1556-6678.2005.tb00348.x

Sackett, D. L., Straus, E., Richardson, W. S. Rosenberg, W., \& Havnes, R. (2000). Evidence-based medicine: How to practice and teach EBM ( $2^{\text {nd }}$ ed. $)$. New York: Churchill Livingstone.

Safran, J. D., \& Messer, S. B. (1997). Psychotherapy integration: A postmodern critique. Clinical Psychology: Science and Practice, 4,140-192. http://dx.doi.org/10.1111/j.1468-2850.1997.tb00106.x

Schultz, D. (2004). Cultural competence in psychosocial and psychiatric care. Social Work in Health Care, 39(3-4), 231-247. http://dx.doi.org/10.1300/J010v39n03_02

Song, S. J. (1999). Using solution-focused therapy with Korean families. In K. S. Ng (Ed), Counseling Asian families from a systems perspective. Alexandra, VA: American Counseling Association.

Svensson, E., J.F. Nygård, T. Sørensen, \& I. Sandanger. (2009). Changes in formal help seeking for psychological distress: The OsLof study. Nordic Journal of Psychiatry, 63(3), 260-6. http://dx.doi.org/10.1080/08039480902880105

Tewary, S. (2005). Indian immigrant women: A theoretical perspective on mental health. Journal of Human Behavior in the Social Environment, 11(1), 1-22. http://dx.doi.org/10.1300/J137v11n01_01

Trivedi, J.K., M. Mishra, \& A. Kendurkar. (2007). Depression among women in the South-Asian region: The underlying issues. Journal of Affective Disorders, 102(1), 219-25. http://dx.doi.org/10.1016/j.jad.2006.09.024

Tseng, W. (2004). Culture and psychotherapy: Asian perspectives. Journal of Mental Health, 13, 151-161. http://dx.doi.org/10.1080/09638230410001669282

U. S. Immigration and Naturalization Service. (2004). 2003 Statistical Year Book. Washington D. C: Author.

Walsh, J. (2003). Endings in clinical practice. Chicago: Lyceum Books, Inc.

Ward, C. (1996). Acculturation. In D. Landis \& R. S. Bhagat (Eds), Handbook in intercultural trainin ( $2^{\text {nd }}$ ed.). Thousand Oaks, CA: Sage.

Wasan, A.D., K. Neufeld, \& G. Jayaram. (2009). Practice patterns and treatment choices among psychiatrists in New Delhi, India. Social Psychiatry and Psychiatric Epidemiology, 44(2), 109-19. http://dx.doi.org/10.1007/s00127-008-0408-z

Watchel, P. L. (2001). Psychoanalysis, behavior therapy, and the relational world. Washington, D.C.: Psychological Association Press.

Wong, S.Y.S., D. Chan, \& P.C. Leung. (2006). Depressive symptoms in middle-aged men: Results from a household survey in Hong Kong. Journal of Affective Disorders, 92(2), 215-20. http://dx.doi.org/10.1016/j.jad.2006.01.027

Yeh, C. J., \& Hwang, K. (1996). The collectivistic nature of ethnic identity development of Asian-American college students. Adolescence, 31(123), 645-661.

Yu, M. (1999). Multimodel assessment of Asian families. In K.S. Ng (Ed.), Counseling Asian families from a Systems perspective. Alexandra, VA: American Counseling Association. 